\title{
ФИНАНСОВЫЕ РЕЗУЛЬТАТЫ ДЕЯТЕЛЬНОСТИ ПРЕДПРИЯТИЯ: СУЩНОСТЬ, КЛАССИФИКАЦИЯ, АНАЛИЗ
}

\author{
(c) 2019 Пайтаева Комета Тахировна \\ кандидат экономических наук, \\ доцент кафедры «Бухгалтерский учёт, анализ и аудит» Института экономики и финансов \\ Чеченский государственный университет, Россия, Грозный \\ E-mail: kometa_1972@mail.ru
}

В данной статье рассматриваются финансовые показатели деятельности предприятия. Приведена классификация видов прибыли, раскрыто экономическое содержание финансовых результатов, обозначена их роль в формировании показателей бухгалтерской (финансовой) отчетности. Определены пути совершенствования методики анализа финансовых результатов предприятия в современных условиях.

Ключевые слова: финансовые результаты, прибыль, бухгалтерская (финансовая) отчетность, классификация, методика анализа финансовых результатов организации, рентабельность.

Глобализация экономики, новации в науке и технике, стремительное развитие информационных технологий привели к многократному усилению конкуренции и повышению нестабильности внешней среды [5, С. 215]. Важнейшей характеристикой внешней среды функционирования экономических субъектов в современном мире является ее непредсказуемость. Предприятиям и организациям становится все труднее адаптироваться к происходящим в политической и социально-экономической сферах изменениям. В этих новых условиях возрастает роль прогнозирования состояния хозяйствующих субъектов и моделирования устоявшейся рыночной парадигмы.

Финансовые результаты финансово-хозяйственной деятельности предприятия зависят от уровня организации, управления, производства в соответствии с которыми формируется система управления предприятием и подбор финансовых менеджеров и бизнес-аналитиков.

Очевидно, что конечной целью любой предпринимательской деятельности является достижение положительного экономического эффекта. Следует отметить, что «система показателей финансовых результатов включает в себя не только абсолютные (прибыль, убыток), но и относительные показатели (рентабельность) эффективности хозяйствования. Чем выше уровень рентабельности, тем выше эффективность хозяйствования [13, С. 246].

Успешность функционирования экономических субъектов в условиях рыночных отноше- ний во многом зависит также от ассортимента выпускаемой продукции, выполняемых работ, оказываемых услуг, то есть от эффективности финансовой, производственной, маркетинговой, инвестиционной деятельности. Предприятие самостоятельно выстраивает структурную политику в зависимости от показателей прибыли и рентабельности того или иного вида продукции (работ, услуг).

Ключевым источником бесперебойной работы предприятия является прибыль, являющаяся показателем эффективной работы предприятия и создающая условия для расширенного производства.

Финансовые результаты характеризуются величиной прибыли (убытка) от текущей, инвестиционной и финансовой деятельности и уровнем рентабельности.

В ходе проведения анализа источников формирования прибыли, ее распределения, определения основных финансовых направлений развития существенную роль играет изучение социально-экономической сущности прибыли. Не менее важная роль в системе критериев эффективности предпринимательства отводится показателям рентабельности, которые характеризуют уровень прибыльности.

Прибыль - это денежное выражение чистого дохода, который зависит от вложенного капитала и оправдывает предпринимательский риск. Изучению специфики анализа финансовых результатов посвящены труды многих ведущих отечественных ученых-экономистов, среди которых 
особое значение имеют работы А.Д.Шеремета, Р.С. Сайфулина, Е.В. Негашева, В.В. Ковалева, Л.А. Бернстайна, Н.Н. Селезневой, А.Ф. Ионовой и др. Данными авторами разработаны методики анализа финансовых результатов деятельности предприятия, определены проблемы и возможные пути их решения, разработана система показателей, характеризующих величину прибыли и уровень рентабельности предприятия.

Прибыль выступает мотивационным фактором для роста экономической эффективности использования ресурсов производства, что является основным источником экономического и социального развития коллектива. В экономическом смысле прибыль - это превышение совокупных доходов над расходами предприятия. В бухгалтерском учете прибыль определяют как разницу между выручкой от реализации продукции и ее себестоимостью.

В свою очередь, выручка от реализации характеризует общий финансовый результат (валовой доход) от реализации продукции (работ, услуг), является одним из основных показателей эффективности финансовой деятельности, который определяет рейтинг предприятия.

Прибыль - это системный показатель эффективности функционирования предприятия. Экономическое содержание прибыли можно охарактеризовать как:

- показатель платежеспособности;

- основной источник расширенного воспроизводства предприятия;

- ключевой индикатор рыночной устойчивости предприятия;

- категория, являющаяся основой роста капитала и расширения бизнеса;

- показатель, характеризующий конкурентоспособность предприятия;

- источник пополнения государственного бюджета и реализации социальных программ.

Профессор Цацулин А.Н. отмечает, что финансовые результаты деятельности предприятий оцениваются количественными и качественными показателями, построенными в установленном порядке, взаимосвязанными и образующими систему. Так, размер прибыли промышленного предприятия может быть определен путем расчета не только количества проданной продукции с учетом сдвигов в ассортименте через оценку ее себестоимости, но и эффективности использования основных средств через оценку фондорентабельности [12, С. 20].
В современных условиях обостряются вопросы управления процессом формирования прибыли, отражающим:

- нацеленность на рост абсолютных значений прибыли в соответствии с требованиями рынка и учетом ограниченности ресурсного обеспечения;

- грамотное построение рационального соотношения между величиной прибыли и финансовыми рисками;

- формирование системы обеспечения достойного уровня доходности инвестированного капитала;

- возрастание объемов инвестиционных вложений за счет роста собственных источников капитала;

- увеличение возможностей материального стимулирования персонала.

Как известно, основой информационного обеспечения анализа прибыли и рентабельности являются данные бухгалтерского учета по счетам результатов 90 «Продажи», 91 «Прочие доходы и расходы», 99 «Прибыли и убытки», 84 «Нераспределенная прибыль (непокрытый убытOK)».

Основными формами бухгалтерской отчётности, используемыми в процессе анализа финансовых результатов, являются:

- бухгалтерский баланс, где отражается нераспределённая прибыль (непокрытый убыток) отчётного и прошлого года;

- отчет о финансовых результатах, который является главным источником информации по показателям прибыли;

- отчет об изменениях капитала, который отражает информацию о нераспределённой прибыли прошлых лет и направлениях ее использования.

Ведущие отечественные экономисты, изучая в своих исследованиях понятие финансовых результатов деятельности хозяйствующих субъектов, имеют иногда различные взгляды на экономическую сущность изучаемой проблемы и подходят с собственной интерпретацией к ее определению.

Так, В.В. Бариленко считает, что «конечным финансовым результатом деятельности любого предприятия, комплексно характеризующим эффективность его работы, является прибыль» [1, C. 163].

О.В. Ефимова подчеркивает, что «действительно конечный результат тот, правом распо- 
ряжаться которым обладают собственники», а в мировой практике под ним подразумевается «прирост чистых активов» [4, С. 344].

В свою очередь, Г.В. Савицкая характеризует финансовые результаты деятельности предприятия «суммой полученной прибыли и уровнем рентабельности» [10, С. 502].

Такой позиции придерживаются многие ученые-экономисты.

Н.Ф. Самсонов отмечает, что «прибыль - денежное выражение основной части денежных накоплений» [11, С. 363].

Понятие «финансовый результат» связано с понятиями «доходы» и «расходы». Категории «доходы», расходы» и «финансовый результат» в российской системе бухгалтерского учета увязаны четко: финансовый результат определяется как разница между доходами и расходами. Такого мнения придерживается Н.П. Кондраков, отмечая, что финансовый результат деятельности экономического субъекта за отчетный период определяется как разница между его доходами и расходами [7, С. 584].

А.А.Канке в своих трудах интерпретирует данное понятие следующим образом: «Финансовый результат характеризует хозяйственную деятельность организации, увеличение или снижение прибыли (убытка) за конкретный промежуток времени» [6, С. 45].

А.Д. Шеремет и Р.С. Сайфулин подчеркивают, что «финансовый результат деятельности предприятия выражается в изменении величины его собственного капитала отчетного периода» [14, С. 84].

В.В.Бочаров определяет исследуемую категорию таким образом: «Прибыль как форма дохода выступает как конечный финансовый результат, создающий необходимые условия для сохранения жизнеспособности и дальнейшего развития предприятия» [2, С. 33].

По мнению Дмитриевой И.М., «финансовый результат деятельности организации за отчётный период определяется показателем прибыли (убытка), который представляет собой разницу между доходами и расходами» [3, С. 206].

Аналогичное определение дают А.И. Нечитайло и Л.Ф. Фомина, считая, что «финансовый результат - конечный экономический итог хозяйственной деятельности организации, определяемый в виде разницы между доходами и расходами» [9, С. 362].

Таким образом, в общем виде финансовый результат представляет собой разность между полученными организацией совокупными доходами и произведенными ею совокупными расходами в процессе всех видов деятельности: текущей, финансовой и инвестиционной.

Применение того или иного алгоритма расчета прибыли и рентабельности зависит от базовых стандартов, нормативно регулирующих финансовую отчетность в стране, от принятой учетной политики предприятия, от уровня и квалификации работника, ответственного за проведение финансового анализа. При этом важно, чтобы результаты анализа способствовали объективной оценке возможностей повышения уровня этих показателей.

Савицкая Г.В. предлагает использовать следующие показатели прибыли:

- маржинальная прибыль, рассчитывается как разница между выручкой и прямыми производственными затратами по реализованной продукции;

- прибыль от реализации продукции, товаров, работ, услуг, рассчитывается путем вычитания из суммы маржинальной прибыли постоянных расходов отчетного периода;

- общий финансовый результат до выплаты процентов и налогов, определяется как финансовый результат от реализации продукции, работ, услуг, доходов и расходов от финансовой, инвестиционной деятельности, внереализационных и чрезвычайных доходов и расходов;

- чистая прибыль - часть прибыли, остающейся в распоряжении экономического субъекта после уплаты налогов, экономических санкций и прочих обязательных платежей;

- капитализированная прибыль - часть чистой прибыли, направляемой на финансирование прироста активов;

- потребляемая прибыль - часть прибыли, расходуемой на выплату заработной платы персоналу, дивидендов или на социальные программы.

Чистую прибыль можно по праву считать основным показателем финансовых результатов и эффективности работы предприятия в целом.

Виды прибыли предприятия по основным классификационным признакам, которые выделяет Нечитайло А.И., представлены в таблице 1.

Отражением доходов по обычным видам деятельности является выручка. В содержание понятия выручка включаются поступления от реализации продукции, доходы от различных 
Таблица 1. Классификация видов прибыли предприятия [8, С. 22]

\begin{tabular}{|l|l|}
\hline Признаки классификации прибыли предприятия & $\begin{array}{l}\text { Виды прибыли по соответствующим признакам } \\
\text { классификации }\end{array}$ \\
\hline Источники образования прибыли в налоговом учете & $\begin{array}{l}\text { Прибыль от продажи продукции (товаров, работ, } \\
\text { Прибыль от внереализационных операций }\end{array}$ \\
\hline $\begin{array}{l}\text { Источники образования прибыли в бухгалтерском } \\
\text { учете }\end{array}$ & $\begin{array}{l}\text { Прибыль от обычных видов деятельности } \\
\text { Прибыль от прочих видов деятельности }\end{array}$ \\
\hline $\begin{array}{l}\text { Источники прибыли по основным видам операций } \\
\text { предприятия }\end{array}$ & $\begin{array}{l}\text { Прибыль от текущих операций } \\
\text { Прибыль от инвестиционых операций } \\
\text { Прибыль от финансовых операций }\end{array}$ \\
\hline $\begin{array}{l}\text { Состав элементов, представленных в отчете } \\
\text { о финансовых результатах }\end{array}$ & $\begin{array}{l}\text { Валовая (маржинальная) прибыль } \\
\text { Прибыль от продаж } \\
\text { Прибыль до налогообложения } \\
\text { Текущий налог на прибыль } \\
\text { Чистая прибыль }\end{array}$ \\
\hline Характер налогообложения прибыли & $\begin{array}{l}\text { Налогооблагаемая (балансовая) прибыль } \\
\text { Не подлежащая налогообложению прибыль }\end{array}$ \\
\hline Характер использования прибыли & $\begin{array}{l}\text { Капитализированная (нераспределенная) прибыль } \\
\text { Потребленная (распределенная) прибыль }\end{array}$ \\
\hline Значение итогового результата хозяйствования & $\begin{array}{l}\text { Прибыль } \\
\text { Убыток - отрицательное значение прибыли }\end{array}$ \\
\hline
\end{tabular}

операций и внереализационные источники денежных потоков. При классификационной характеристике различных доходов они подразделяются на выручку от реализации и прочие поступления, включающие как доходы от операционных и внереализационных видов деятельности, так и доходы от чрезвычайных ситуаций.

Анализ хозяйственной деятельности включает два крупных раздела:

- финансовый анализ;

- управленческий производственный анализ.

Финансовый анализ позволяет комплексно изучать следующие вопросы:

- дать полную оценку финансовым результатам хозяйственной деятельности;

- оценить уровень финансового положения и предсказать направление его возможного изменения;

- системно оценить уровень эффективности бизнеса и рыночные позиции предприятия.

Целевой установкой при проведении финансового анализа выступает возможность расчета определенного количества информативных показателей, в которых находит отражение финан- совое состояние предприятия, структурные изменения активов и пассивов, оценка состояния расчетов и др. При этом текущее состояние изучается для предвидения перспектив развития предприятия.

Подводя итог изложенному выше, можно признать следующую последовательность этапов анализа финансовых результатов как наиболее целесообразную:

- анализ динамики, структуры и состава прибыли до налогообложения;

- факторный анализ финансовых результатов от обычных видов деятельности;

- факторный анализ финансовых результатов от прочих видов деятельности, налогооблагаемой и чистой прибыли;

- оценка динамики формирования и использования чистой прибыли;

- анализ показателей рентабельности;

- выявление и оценка потенциальных резервов роста суммы прибыли и уровня рентабельности;

- разработка и принятие оптимальных управленческих решений по использованию выявленных резервов в производстве.

\section{Библиографический список}

1. Бариленко В.В. Анализ хозяйственной деятельности.-М.: Изд-во Омега-Л. - 2009.

2. Бочаров В.В. Финансовый анализ.-СПб.: Питер. -2009.

3. Дмитриева И.М. Бухгалтерский учет и аудит: учебное пособие / И.М. Дмитриева.- М.: Юрайт, 2013.- С. 206. 
4. Ефимова О.В. Финансовый анализ: современный инструментарий для принятия экономических решений.-М.: Изд-во Омега-Л, 2010.

5. Казакова Н.А Финансовый анализ.- М.: Юрайт. - 2016.

6. Канке А.А. Анализ финансово-хозяйственной деятельности предприятия.- М.: ИД ФОРУМ, НИЦ ИНФРА-М.- 2015.

7. Кондраков Н.П. Бухгалтерский учет (финансовый и управленческий). - М.: ИНФРА-М.-2018.

8. Нечитайло А. И. Учет финансовых результатов и распределения прибыли.-СПб.: Питер.-2015.-c.22.

9. Нечитайло А.И., Фомина Л.Ф. Бухгалтерский финансовый учет для бакалавров.- Ростов н/Д: Феникс.2014.

10. Савицкая Г.В. Анализ хозяйственной деятельности предприятия.-М.: ИНФРА-М, 2015.

11. Самсонов Н. Ф. Финансовый менеджмент.- М.: Финансы, ЮНИТИ, 2015.

12. Цацулин А.Н. Экономический анализ.-СПб.: Питер.-2014.

13. Чечевицына, Л.Н., Чуев И.Н. Анализ финансово-хозяйственной деятельности.- М.: «Дашков и Кํ․- 2015.

14. Шеремет А.Д. Методика финансового анализа.-М.: ИНФРА-М.-2010. 